\title{
Tamoxifen induces ultrastructural alterations in membranes of Bacillus Stearothermophilus
}

\author{
C. Luxo a,b,c,*, A.S. Jurado ${ }^{c}$, Vitor M.C. Madeira ${ }^{c}$, M.T. Silva ${ }^{d}$ \\ ${ }^{a}$ Laboratório de Microbiologia, Faculdade de Farmácia, Rua Couraça dos Apóstolos, no. 51, r/c, Universidade de Coimbra, \\ 3000 Coimbra, Portugal \\ ${ }^{\mathrm{b}}$ Centro de Estudos Farmacêuticos, Universidade de Coimbra, Coimbra, Portugal \\ ${ }^{\mathrm{c}}$ Centro de Neurociencias, Universidade de Coimbra, Coimbra, Portugal \\ ${ }^{\mathrm{d}}$ Instituto de Biologia Molecular e Celular da Universidade do Porto, Porto, Portugal
}

Accepted 30 June 2003

\begin{abstract}
Tamoxifen (TAM), a non-steroid antiestrogen, is the mostly used drug for chemotherapy and chemoprevention of breast cancer. However, the mechanisms by which TAM inhibits cell proliferation in breast cancer are not fully understood. TAM strongly incorporates in biomembranes and a variety of effects have been assigned to biophysical and biochemical interactions with membranes. Therefore, a better understanding of the physicochemical basis of interaction of TAM with biomembranes is essential to elucidate the molecular mechanisms of action. A strain of Bacillus stearothermophilus has been used as a model to clarify the interaction of TAM with the cell membrane. TAM effects on the ultrastructure of membranes of this bacterium were evaluated by electron microscopy. Important ultrastructural alterations were observed in B. stearothermophilus treated with TAM, namely change in the geometry of the membrane profile from asymmetric to symmetric, disaggregation of ribosomes, coagulation of the cytoplasmic matrix, occurrence of mesossomes, appearance of fractures in membranes and the alteration of the ultrastructure of cell wall. These ultrastructural alterations confirm that TAM is a membrane-active drug and that membrane damage may be involved in molecular mechanisms of cell death induced by this drug.
\end{abstract}

(C) 2003 Elsevier Ltd. All rights reserved.

Keywords: Tamoxifen; Bacillus stearothermophilus; Ultrastructural membrane alterations

\section{Introduction}

Tamoxifen (TAM), a non-steroid antiestrogen, is the mostly used drug for chemotherapy and chemoprevention of breast cancer (Neven and Vernaeve, 2000; Radmacher and Simon, 2000). Although tamoxifen is usually considered an estrogen antagonist, it is now evident that the antiproliferative effects may involve mechanisms not restricted to the classical oestrogen receptor (ER) binding model (Kon, 1989). TAM has been reported to inhibit the growth of ER-negative breast cancer cells and other types of cells that lack ER (Croxtall et al., 1994; Van den Koedijke et al., 1994;

\footnotetext{
Abbreviations: TAM; Tamoxifen; ER; Oestrogen receptor

* Corresponding author. Tel.: +351-239-852567; fax: + 351-39852569.

E-mail address: crisluxo@ci.uc.pt (C. Luxo).
}

Charlier et al., 1995). These mechanisms underlying the ER-independent inhibition of tumor cell growth by TAM are not yet understood. Thus, extensive studies have been performed and multiple cellular effects have been described, namely binding to antiestrogen binding sites (Lazier, 1987; Shuterland et al., 1980), antioxidant action (Custódio et al., 1994; Wiseman et al., 1990), inhibition of protein kinase C (O'Brian, 1986; Bignon et al., 1991), inhibition of cAMP phosphodiesterase (Lam, 1984; Rowlands et al., 1990), inhibition of of a nucleoside transporter protein (Cai and Lee, 1996), antagonism of calmodulin by direct interaction with this protein (Lopes et al., 1990) and induction of apoptosis (Gelman, 1996; Ellerby et al., 1997).

TAM strongly incorporates in biomembranes (Custódio et al., 1991) interacting with lipids (Custódio et al., 1993; Luxo et al., 1996) and proteins (Lopes et al., 1990; Custódio et al., 1996). A variety of effects of TAM have 
been assigned to biophysical and biochemical interactions with membranes. These effects include the stimulation of ATP hydrolysis (Custódio et al., 1996; Chen et al., 1999) and the decrease in the energetic efficiency of the $\mathrm{Ca}^{2+}$-pump of sarcoplasmic reticulum (Custódio et al., 1996), modifications in the morphology and structure of the breast tumor cell membranes, potentially responsible for its estrogen-independent antiproliferative activity (Sica et al., 1984), hemolytic effects (Cruz Silva et al., 2000), mitochondrial swelling (Custódio et al., 1998) and proton leak across the mitochondrial inner membrane (Cardoso et al., 2002). Therefore, biomembranes are likely targets of TAM.

A better understanding of the physicochemical basis of interaction of TAM with biomembranes is essential to test the possibility of TAM cytotoxicity being dependent on its membrane interaction.

Biomembranes are common components to all living structures and the first target of contact for xenobiotics, perhaps the most important for lipophilic compounds. Mammalian membranes are undoubtly the most suitable models to study membrane interactions of pharmacological compounds, TAM included. However, due to the high complexity, other membrane models, e.g. artificial membranes composed of synthetic lipids, are usually used (Balasubramanian and Straunbinger, 1994; Canaves et al., 1991; Custódio et al., 1993; Wright and White, 1986). Also, prokaryotic membranes, with a simple phospholipid composition as compared with eukaryotic membranes, have been used as suitable models (Sikkema et al., 1995). They are similar to the actual target membranes owing to a similar lipid composition (including several phospholipids classes and species), although with a simple structure; furthermore, bacterial membranes are easy to isolate, yielding very pure preparations, since there are no intracellular compartments in most prokaryots and a single membrane involves the cytoplasm in Gram-positive Eubacteria. Finally, bacterial phospholipids of eubacteria are structurally similar to the eukaryotic counterparts (Ratledge and Wilkinson, 1988) and they also play similar roles to eukaryotic lipids (Russel, 1989), providing a fluid bilayer to embed integral proteins preventing hydrophobic mismatch (Bloom et al., 1991). Bacillus stearothermophilus has been extensively used in our laboratory to study the toxic effects of several xenobiotics (Luxo et al., 1996; Donato et al., 1997a; Rosa et al., 2000a). In addition to general advantages of prokaryotic cells as mentioned above, B. stearothermophilus has the ability to overcome the threatening of adverse environmental conditions, namely chemical stress, by undergoing membrane lipid composition changes (Luxo et al., 1998; Donato et al., 1997b, Rosa et al., 2000b). On the other hand, bacterial growth inhibition has shown a good relationship with other bioindicators of chemical stress in eukaryotic cells, e.g., the respiratory activity of rat liver mitochondria (Donato et al., 1997c).

Previous studies show that TAM inhibits growth of B. stearothermophilus and perturbs the physical behaviour of bacterial membrane lipids (Luxo et al., 1996). Additionally, B. stearothermophilus modifies membrane lipid composition in response to the addition of TAM to the growth medium in order to compensate the perturbing effects of this drug (Luxo et al., 1998). Although, B. stearothermophilus is endowed with efficient molecular mechanisms of adaptation, TAM concentrations higher than $10 \mu \mathrm{m}$ completely inhibit growth and induce cell death (Luxo et al., 1998). Molecular mechanisms of cell death induced by this drug remain obscure, but membrane damage may putatively be involved. In our study, we evaluated TAM effects on the ultrastructure of B. stearothermophilus by electron microscopy attempting to clarify antiproliferative mechanisms of TAM.

Studies of TAM effects on the ultrastructure of membranes of $B$. stearothermophilus may be extrapolated to other membrane systems, namely eukaryotic, and may contribute to clarify antiproliferative mechanisms of TAM.

\section{Materials and methods}

\subsection{Chemicals}

Tamoxifen was obtained from Sigma Chemical Co. (St Louis, MO, USA).

\subsection{Cultures}

The strain of B. stearothermophilus was isolated from discs impregnated with spores supplied by Mast Laboratoires, UK (lot no. 8879). Stock cultures were maintained at $-80{ }^{\circ} \mathrm{C}$. Liquid cultures were started with an early stationary inoculum from a culture medium ( $\mathrm{L}$ Broth: tryptone $5 \mathrm{~g}$, yeast extract $2.5 \mathrm{~g}$, sodium chloride $1.25 \mathrm{~g}, 1 \mathrm{M}$ sodium hydroxide $2 \mathrm{ml}, 100 \mathrm{~mm}$ cystine in 1 $\mathrm{M} \mathrm{HCl} 1 \mathrm{ml}, \mathrm{H}_{2} \mathrm{O} 1000 \mathrm{ml}$ ) and were grown in 11 Erlenmeyer flasks containing $200 \mathrm{ml}$ of the same medium shaken at $100 \mathrm{rpm}$ in a New Brunswick water-bath shaker, at $65{ }^{\circ} \mathrm{C}$. Tamoxifen from a concentrated ethanolic solution was added to the cultures, in the exponential phase, to obtain concentrations ranging from 5 to $10 \mu \mathrm{M}$. The bacterial growth in media containing tamoxifen had to be performed in silanized Erlenmeyer flasks, since this drug binds strongly to glass material (Custódio et al., 1991).

Growth was measured by turbidimetry at $610 \mathrm{~nm}$ in a Spectronic 201 (Milton Roy Co., Rochester, NY, USA) instrument. 


\subsection{Electron microscopy}

Two millilitres of glutaraldehyde $25 \%$ were added to aliquots $(20 \mathrm{ml})$ of the different cultures (with and without TAM). After centrifugation at $10,000 \mathrm{~g}$ for 5 min, the cells were resuspended in glutaraldehyde at $2.5 \%$ in $0.1 \mathrm{M}$ cacodylate buffer, $\mathrm{pH} 7.0$, for $4 \mathrm{~h}$. After, they were whashed twice with $50 \mathrm{~mm}$ cacodylate buffer supplemented with $10 \mathrm{~mm} \mathrm{CaCl}_{2}$ (pH 6.4) and fixed at room temperature, for $2 \mathrm{~h}$, in $1 \%$ osmium tetroxide $\left(\mathrm{OsO}_{4}\right)$ in veronal-acetate buffer, supplemented with 10 $\mathrm{mm} \mathrm{CaCl}_{2}$ (Silva and Macedo, 1983). After fixation, the samples were dehydrated with ethanol and embedded in Epon. Ultrathin sections were obtained with an LKB Ultrotome III fitted with a diamond knife and stained with uranyl acetate and lead citrate (Silva et al., 1987). Observations and micrographs were made with a Zeiss EM 10C electron microscope.

\section{Results}

\subsection{Effects of TAM on the growth of \\ B. stearothermophilus}

The strain of Bacillus stearothermophilus was grown at $65^{\circ} \mathrm{C}$ (optimal temperature) in a culture medium (LBroth) and TAM was added in a concentration range from 5 to $10 \mu \mathrm{M}(5 ; 7.5 ; 10 \mu \mathrm{M})$ to the cultures in exponential phase. Addition of TAM during exponential phase induced bacterial growth inhibition as a function of concentration (Fig. 1).

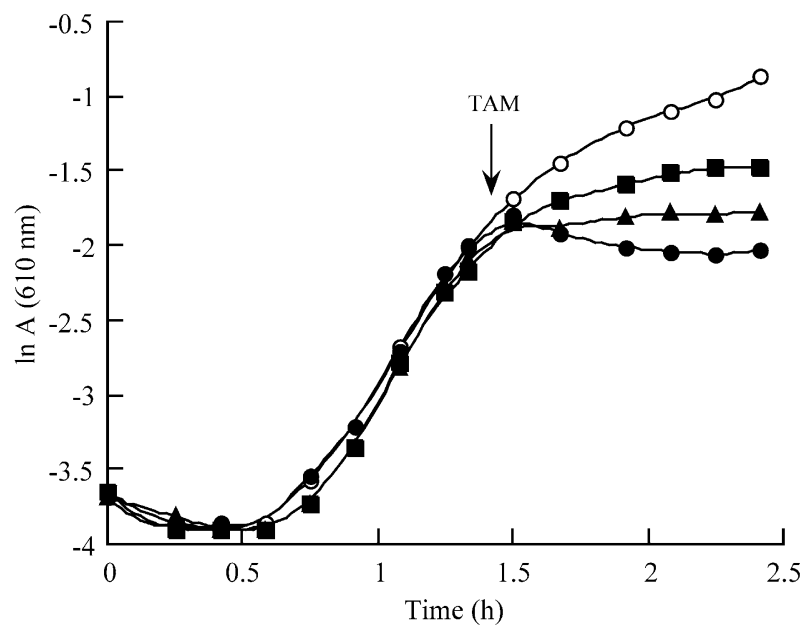

Fig. 1. Effect of tamoxifen addition on the growth of cultures of $B$. stearothermophilus at $65{ }^{\circ} \mathrm{C}$. Growth of cultures without tamoxifen $(\bigcirc)$ addition in exponential phase or with addition of $5 \mu \mathrm{M}(\boldsymbol{\square}), 7.5$ $\mu \mathrm{M}(\diamond)$ or $10 \mu \mathrm{M}(\bullet)$ tamoxifen. Growth was measured as absorbance at $610 \mathrm{~nm}$. The results shown are typical of three separate experiments.

\subsection{Effects of TAM on the ultrastructure of Bacillus stearothermophilus}

Addition of TAM to the growth medium of B. stearothermophilus induced important ultrastructural alterations in membranes of B. stearothermophilus. Aspects of control B. stearothermophilus are shown in Fig. 2. The cytoplasmic membrane (MC) is continuous and shows the asymmetric geometry typical of Gram-positive bacteria. The cell wall (PC) is intact and the fibrillar nucleoide $(\mathrm{N})$ and abundant ribosomes in the cytoplasm are clearly visible. The treatment with TAM resulted in important ultrastructural alterations namely, change in the membrane staining pattern from the normal asymmetric to symmetric geometry, the disaggregation of ribosomes, the coagulation of the cytoplasmic matrix and formation of complex mesosome-like membranous structures (Figs. 3 and 4). The cell wall remained unchanged (Figs. 3 and 4). After longer treatment times or with high concentrations, the membrane alterations were more dramatic, with fracturing and membrane solubilization and the cell wall appears extensively damaged (Fig. 5). Cell wall breakage may occur (arrow) with leakage of cytoplasmic material (Fig. 5).

\section{Discussion}

It is clearly shown that TAM induces important membrane ultrastructural alterations in $B$. stearothermophilus. The change of the asymmetric geometry of cytoplasmic membranes of Gram-positives to sym-

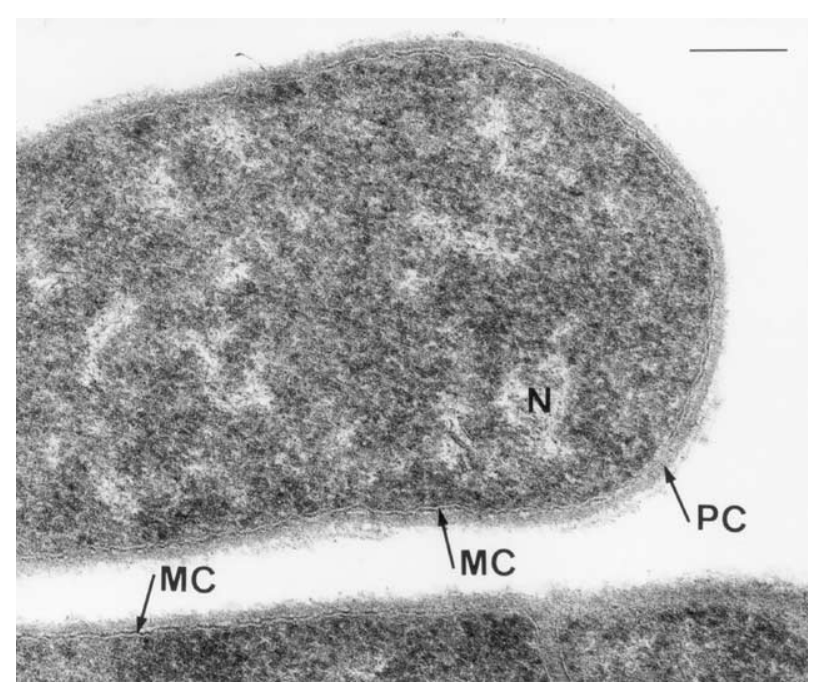

Fig. 2. Control cell of Bacillus stearothermophilus, showing the asymmetric and continuous membrane profile (MC) and the intact cell wall (PC). Notice the fibrillar nucleoside $(\mathrm{N})$ and the abundant ribosomes. $\mathrm{Bar}=0.2 \mu \mathrm{M}$. 
metric geometry indicates membrane damage and occurs in several situations. This is the case in which Gram-positive bacteria are damaged by lysis (Silva, 1967) or by treatment with membrane active molecules, namely, local anesthetics (Silva et al., 1979), phenethyl alcohol (Silva et al., 1976) and organic solvents (Silva et al., 1978). This change of the membrane profile is usually a very early alteration and, therefore, it represents a useful marker for membrane damage. Bacterial ribosome disappearance has been also observed for several damaged Gram-positive bacteria (Silva and Macedo, 1983). Several mechanisms can be advanced to explain ribosome disappearance: ion leakage associated with the loss of selective permeability as a result of membrane damage at the beginning of the degradative

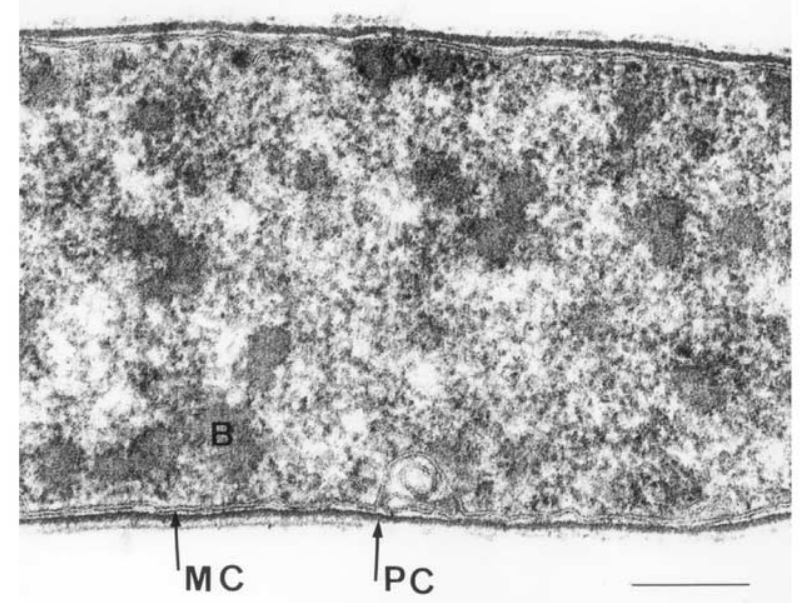

(a)

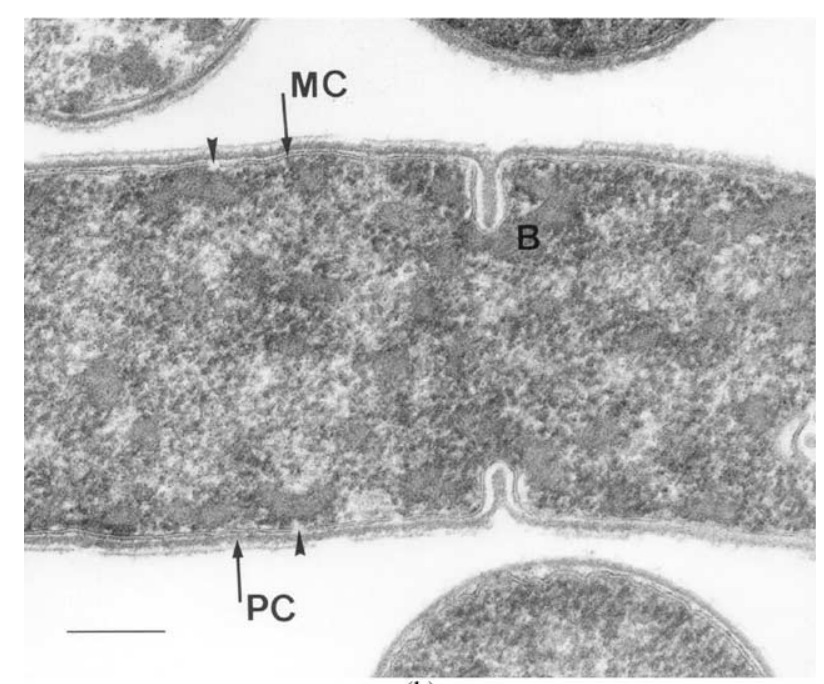

(b)

Fig. 3. B. stearothermophilus cells treated with TAM ((a)-7.5 $\mu \mathrm{M} / 110$ min.; (b)-10 $\mu \mathrm{M} / 110 \mathrm{~min}$ ). Cells with a change in the cytoplasmic membrane (MC) profile from asymmetric to symmetric and with the appearance of fractures (arrows). Notice the coagulated cytoplasm with dense blocks (B) and ribosomes partially disagregated. The cell wall $(\mathrm{PC})$ remains intact. $\mathrm{Bar}=0.2 \mu \mathrm{m}$. process, since ribosome stability depends on the intracellular ionic environment (Silva and Macedo, 1983); activation of bacterial endogenous RNases occurring in situations of membrane damage (Santos Mota et al., 1971).

Considering that biomembranes are structurally similar in eukaryotic and prokaryotic cells, it is predictable that TAM may also induce similar ultrastructural alterations in eukaryotic membranes. Sica et al. have shown that tamoxifen induces modifications in the morphology and structure of human breast cancer cell membranes (CG-5) and suggest that these alterations could be partially responsible for its oestrogen-independent antiproliferative activity (Sica et al., 1984).

Several effects of TAM have been suggested to be a consequence of membrane damage. The stimulation of ATP hydrolysis (Custódio et al., 1996; Chen et al., 1999) and the decrease energetic efficiency of sarcoplasmic reticulum $\mathrm{Ca}^{2+}$-pump induced by TAM would be related with structural defects induced by this drug on membranes (Custódio et al., 1996). In the same way, mitochondrial swelling and membrane potential depolarisation induced by TAM reflect a direct action of this drug on the mitochondrial inner membrane structure (Custódio et al., 1998). Hemolytic anemia, observed in patients treated with TAM, has also been suggested to result from structural defects in the erythrocyte membrane induced by this drug (Cruz Silva et al., 2000). Moreover, TAM affects mitochondrial bioenergetics (Cardoso et al., 2001) and induces proton leak across the mitochondrial inner membrane (Cardoso et al., 2002) as a consequence of the destructive effects in the structural integrity of the mitochondrial inner membrane. Accordingly, the ultrastructural alterations observed in B. stearothermophilus confirm that TAM is a membrane-active drug. The disruption of the structural characteristics of biomembranes by TAM may

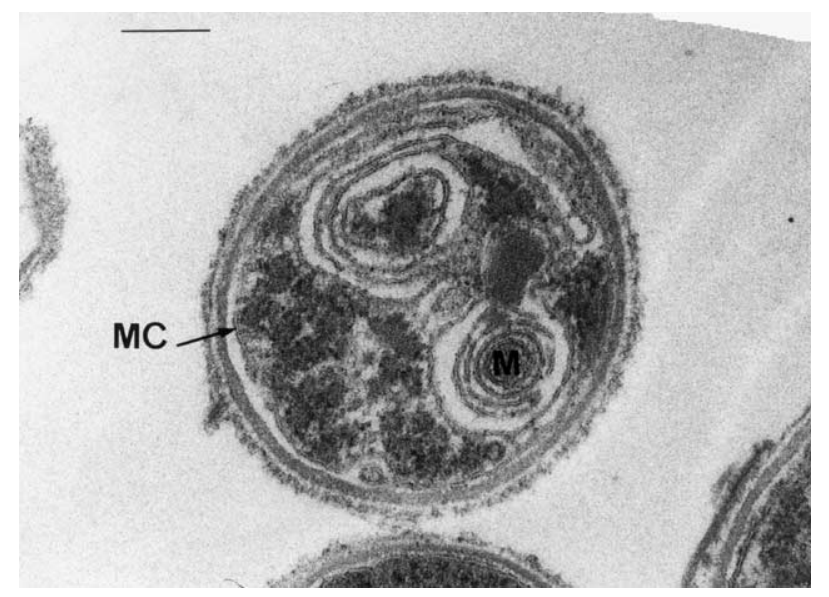

Fig. 4. B. stearothermophilus cell treated with TAM (10 $\mu \mathrm{M} / 110 \mathrm{~min})$. Transversal section of a cell showing symmetric cytoplasmic membrane profiles (MC) with zones of extensively solubilization. Notice two lamellar mesossomes (M). Bar $=0.2 \mu \mathrm{M}$. 


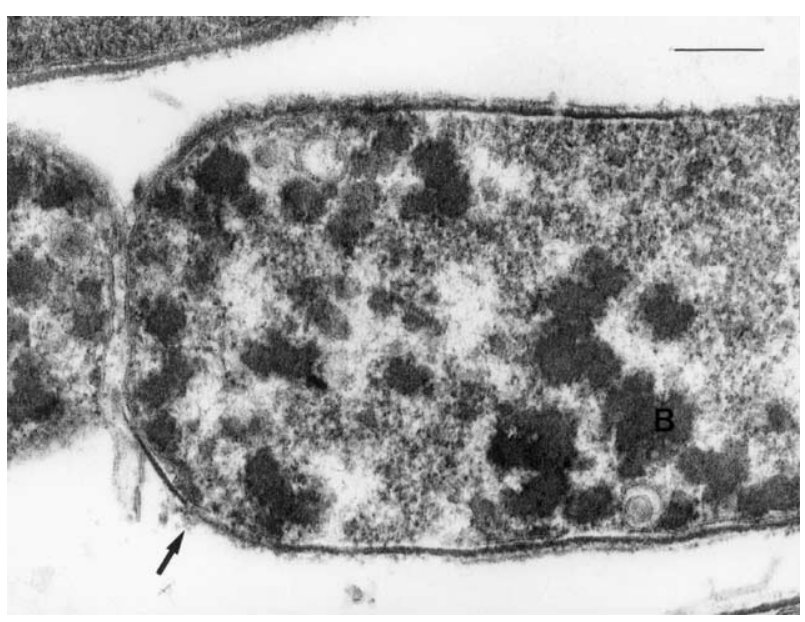

Fig. 5. B. stearothermophilus cell treated with TAM $(10 \mu \mathrm{M} / 140 \mathrm{~min})$. The cytoplasmic membrane is extensively solubilized. The membrane remants have a symmetric profile. Notice the blocks of compact cytoplasmic matrix (B). The cell wall is extensively damaged with cell wall disruption (arrow) and leakage of cytoplasmic material. Bar $=0.2 \mu \mathrm{M}$.

contribute for the multiple mechanisms of anticancer action not related to the oestrogen receptors and may be involved in molecular mechanisms of cell death induced by this drug.

\section{References}

Balasubramanian, S.V., Straubinger, R.M., 1994. Taxol lipid interactions: taxol-dependent effects on the physical properties of model membranes. Biochemistry 33, 8941-8947.

Bloom, M., Evans, E., Mouritsen, O.G., 1991. Physical properties of the fluid lipid-bilayer component of cell membranes: a perspective. Quarterly Reviews of Biophysics 24, 293-397.

Cai, J., Lee, C.W., 1996. Tamoxifen inhibits nitrobenzylthioinosinesensitive equilibrative uridine transport in human MCF-7 breast cancer cells. Biochemical Journal 320, 991-995.

Canaves, J.M., Ferragut, J.A., Gonzalez-Ros, J.M., 1991. Verapamil prevents the effects of daunomycin on the thermotropic phase transition of model lipid bilayers. Biochemical Journal 279, 413-418.

Cardoso, C.M.P., Custódio, J.B.A., Almeida, L.M., Moreno, A.J.M., 2001. Mechanisms of the deleterious effects of tamoxifen on mitochondrial respiration rate and phosphorylation efficiency. Toxicology and Applied Pharmacology 176, 145-152.

Cardoso, C. M. P., Moreno A. J. M., Almeida, L. M. and Custódio, J. B. A. (2002) 4-Hydroxytamoxifen induces slight uncoupling of mitochondrial oxidative phosphorylation system in relation to the deleterious effects of tamoxifen. Toxicology in press.

Charlier, C., Chariot, A., Antoine, N., Merville, M., Gielen, J., Castronovo, V., 1995. Tamoxifen and its active metabolite inhibit growth of estrogen receptor-negative MDA-MB-345 cells. Biochemical Pharmacology 49, 351-358.

Chen, Y., Schindler, M., Simon, S.M., 1999. A mechanism for tamoxifen-mediated inhibition of acidification. Journal of Biological Chemistry 274, 18364-18373.

Croxtall, J.D., Emmas, C., White, J.O., Choudhary, Q., Flower, R.J., 1994. Tamoxifen inhibits growth of oestrogen receptor-negative A549 cells. Biochemical Pharmacology 47, 197-202.

Cruz Silva, M.M., Madeira, V.M.C., Almeida, M.L., Custódio, J.B.A., 2000. Hemolysis of human erythrocytes induced by tamox- ifen is related to disruption of membrane structure. Biochimica et Biophysica Acta 1464, 49-61.

Custódio, J.B.A., Almeida, L.M., Madeira, V.M.C., 1991. A reliable and rapid procedure to estimate drug partitioning in biomembranes. Biochemical and Biophysical Research Communications 176, 10791085.

Custódio, J.B.A., Almeida, L.M., Madeira, V.M.C., 1993. The anticancer drug tamoxifen induces changes in the physical properties of model and native membranes. Biochimica et Biophysica Acta 1150, $123-129$.

Custódio, J.B.A., Almeida, L.M., Madeira, V.M.C., 1994. Tamoxifen and hydroxytamoxifen as intramembranous inhibitors of lipid peroxidation. Evidence for peroxyl radical scavenging activity. Biochemical Pharmacology 47, 1989-1998.

Custódio, J.B.A., Almeida, L.M., Madeira, V.M.C., 1996. The effect of the anticancer drugs tamoxifen and hydroxytamoxifen on the calcium pump of isolated sarcoplasmic reticulum vesicles. Toxicology in vitro $10,523-531$.

Custódio, J.B.A., Moreno, A.J.M., Wallace, K.B., 1998. Tamoxifen inhibits induction of the mitochondrial permeability induced by $\mathrm{Ca}^{2+}$ and inorganic phosphate. Toxicoloy and Applied Pharmacology $152,10-17$.

Donato, M.M., Jurado, A.S., Antunes-Madeira, M.C., Madeira, V.M.C., 1997a. Bacillus stearothermophilus as a model to evaluate membrane toxicity of a lipophilic environmental pollutant (DDT). Archives Environmental Contamination and Toxicology 33, 109116.

Donato, M.M., Jurado, A.S., Antunes-Madeira, M.C., Madeira, V.M.C., 1997b. Effects of lipophilic environmental pollutant (DDT) on the phospholipid and fatty acid contents of Bacillus stearothermophilus. Archives Environmental Contamination and Toxicology $33,341-349$.

Donato, M.M., Jurado, A.S., Antunes-Madeira, M.C., Madeira, V.M.C., 1997c. Comparative study of toxic actions of 2,2-bis(p-chlorophenyl)-1,1,1-trichloroethane 2,2-bis-(p-chlorophenyl)-1,1dichloroethylene on the growth and respiratory activity of a microorganism used as model. Applied Environmental Microbiology 63, 4948-4951.

Ellerby, H.M., Martin, S.J., Ellerby, L.M., Naiem, S.S., Rabizadeh, S., Salvesen, G.S., Casiano, C., Cashman, N.R., Green, D.R., Bredsen, D.E., 1997. Establishment of a cell-free system of neuronal apoptosis: comparison of premitochondrial mitochondrial and posmitochondrial phases. Journal of Neuroscience 17, 6165-6178.

Gelmann, E.P., 1996. Tamoxifen induction of apoptosis in estrogen receptor-negative cancers: new tricks for na old dog? Journal of National Cancer Institute 88, 224-226.

Kon, O.L., 1989. Estrogens, antiestrogens and cell proliferation. Bioessays 10, 210-214.

Lam, H.-Y., 1984. Tamoxifen is a calmodulin antagonist in the activation of cAMP phosphodiesterase. Biochemical and Biophysical Research Communications 118, 27-32.

Lazier, C.B., 1987. Interactions of tamoxifen in the chicken. Journal of Steroid Biochemistry and Molecular Biology 27, 882-887.

Lopes, M.C.F., Vale, M.G.P., Carvalho, A.P., 1990. $\mathrm{Ca}^{2+}$-dependent binding of tamoxifen to calmodulin isolated from bovine brain. Cancer Research 50, 2753-2758.

Luxo, C., Jurado, A.S., Custódio, J.B.A., Madeira, V.M., 1996. Use of Bacillus stearothermophilus as a model to study tamoxifen-membrane interactions. Toxicology in vitro 10, 463-471.

Luxo, C., Jurado, A.S., Madeira, V.M., 1998. Lipid composition changes induced by tamoxifen in a bacterial model system. Biochimica et Biophysica Acta 1369, 71-84.

Neven, P., Vernaeve, H., 2000. Guidelines for monitoring patients taking tamoxifen treatment. Drug Saffety 22, 1-11.

O'Brian, C.A., Liskamp, R.M., Solomon, D.H., Weinstein, I.B., 1986. Triphenyl ethylenes: a new class of protein kinase inhibitors. Journal of the National Cancer Institute 76, 1243-1246. 
Radmacher, M.D., Simon, R., 2000. Estimation of tamoxifen's efficiency for preventing the formation and growth of breast tumors. Journal of the National Cancer Institute 92, 48-53.

Ratledge, C., Wilkinson, S.G., 1988. Fatty acids, related and derived lipids. In: Ratledge, C., Wilkinson, S.G. (Eds.), Microbial Lipids. Vol. I. Academic Press, London, pp. 2-53.

Rosa, S.M.L.J., Antunes-Madeira, M.C., Matos, M.J., Jurado, A.S., Madeira, V.M.C., 2000a. Amiodarone interactions with membrane lipids and with growth of Bacillus stearothermophilus used as a model. Applied Biochemistry and Biotechnology 87, 165-175.

Rosa, S.M.L.J., Antunes-Madeira, M.C., Matos, M.J., Jurado, A.S., Madeira, V.M.C., 2000b. Lipid composition and dynamics of cell membranes of Bacillus stearothermophilus adapted to amiodarone. Biochimica et Biophysica Acta 1487, 286-295.

Rowlands, M.G., Parr, I.B., McGague, R., Jarman, M., Goddard, P.M., 1990. Variation of the inhibition of calmodulin dependent cyclic AMP phosphodiesterase amongst analogues of tamoxifen; correlation with cytotoxicity. Biochemical Pharmacology 40, 283-289.

Russell, N.J., 1989. Functions of lipids: structural roles and membranes functions. In: Ratledge, C., Wilkinson, S.G. (Eds.), Microbial Lipids. Vol. II. Academic Press, London, pp. 279-365.

Santos-Mota, J.M., Silva, M.T., Carvalho-Guerra, F., 1971. Ultrastructural and chemical alterations induced by dicumarol in Streptococcus faecalis. Biochimica et Biophysica Acta 249, 114-121.

Shuterland, R.L., Murphy, L.C., Foo, M.S., Green, M.D., Whybourn, A.M., Krozowski, Z.S., 1980. High-affinity anti-oestrogen binding site distinct from the oestrogen receptor. Nature 288, 273-275.

Sica, G., Natoli, C., Marchetti, P., Piperno, S., Iacobeli, S., 1984. Tamoxifen induced membrane alterations in human breast cancer cells. Journal of Steroid Biochemistry 20, 425-428.
Sikkema, J., de Bont, J.A.M., Poolman, B., 1995. Mechanisms of membrane toxicity of hydrocarbons. Microbiological Reviews 59, 201-222.

Silva, M.T., 1967. Electron microscopic aspects of membrane alterations during bacterial cell lysis. Experimental Cell Research 46, 245 251.

Silva, M.T., Macedo, P., 1983. M A comparative ultrastructural study of the membranes of Mycobacterium leprae and of cultivable Mycobacterium. Biology of the Cell 47, 383-386.

Silva, M.T., Appelberg, R., Silva, M.N.T., Macedo, P.M., 1987. In vivo killing and degradation of Mycobacterium aurum with mouse peritoneal macrophages. Infection and Immunity 55, 2006-2016.

Silva, M.T., Sousa, J.C.F., Balassa, G., 1978. Ultrastructural effects of chemical agents and moist heat on Bacillus subtilis. Annals of Microbiology 129B, 363-375.

Silva, M.T., Sousa, J.C.F., Macedo, M.A.E., Polónia, J., Parente, A.M., 1976. Effects of phenetyl alcohol on Bacillus and Streptococcus. Journal of Bacteriology 127, 1359-1369.

Silva, M.T., Sousa, J.C.F., Polónia, J.J., Macedo, P.M., 1979. Effects of local anesthetics on bacterial cells. Journal of Bacteriology 137, 461-468.

Van den Koedijk, C.D.M.A., Blankenstein, M.A., Thijssen, J.H.H., 1994. Speculation on the mechanism of action of triphenylethylene antioestrogens. Biochemical Pharmacology 47, 1927-1937.

Wiseman, H., Laughton, M.J., Arnestein, H.R.V., Cannon, M., Haliwell, B., 1990. The antioxidant action of tamoxifen and its metabolites: Inhibition of lipoperoxidation. FEBS Letters 236, 192-194.

Wright, S.E., White, J.C., 1986. Membrane ordering effects of the anticancer agent VM-26. Biochimica et Biophysica Acta 863, 297304. 